UDC 343.14

LBC 67.410.204

\title{
SOME ASPECTS OF THE CRIMINALISTIC CHARACTERISTICS OF CRIMES COMMITTED IN THE SPHERE OF THE MILITARY-INDUSTRIAL COMPLEX OF RUSSIA IN THE CONTEXT OF THE NATIONAL SECURITY
}

\author{
Svyatoslav Yu. Biryukov \\ Volgograd Academy of the Ministry of Interior of Russia, Volgograd, Russian Federation \\ Nadezhda T. Trishina \\ Volgograd State University, Volgograd, Russian Federation
}

\begin{abstract}
Introduction: there is no doubt that the existence of a powerful and efficient army in the state, in addition to a developed and stable economy, in the conditions of the modern world is one of the most reliable guarantees of the stable international situation of a country, respectful and adequate attitude towards it by other states, and ultimately the ensuring of its national security.

The strengthening of the combat capability of the Russian army has been one of the most important national projects in recent years. One of the most important activities in this area is the rearmament of the army, equipping it with the new military equipment and modern weapons.

The unconditional relevance of such activities was confirmed by the recent operation of the Russian Armed forces in the Syrian Arab Republic, where the capabilities of the modern military technology product of the Russian defense industry were repeatedly demonstrated. However, it is no secret that these "injections" of funds also serve as a prerequisite for their theft, which, in our opinion, is a dangerous destabilizing factor that has an extremely negative impact on the state of the national security of this country, as evidenced by the reports of the Prosecutor General of Russia Yu.Ya. Chaika.

The analysis of the investigative and judicial practice shows not always satisfactory quality of the investigation of crimes committed in the field of the defense industry. The quality is directly dependent on the level of forensic support of the investigation process itself, including the availability of evidence-based recommendations on the organizational basis for their disclosure and investigation.

In this regard, the authors set a goal to reveal particular, the most significant elements of the criminalistic characteristics of this type of crime. Methods: the methodological framework for this study is a set of methods of scientific cognition, among which the main are the methods of information processing and logical analysis, synthesis, induction, deduction and generalization. Results: the author's filling of certain elements of the criminalistic characteristics of crimes committed in the sphere of the military-industrial complex of Russia based on the judicial and investigative practice makes it possible to use them in the practical activities of the authorized law enforcement officials in the course of detection and investigation of the above-mentioned crimes. Conclusions: the study has revealed some elements of the criminalistic characteristics of crimes of this type for law students, teachers of law schools, as well as practitioners in order to better understand the features of the investigation of crimes in the sphere of the military-industrial complex.
\end{abstract}

Key words: national security, rearmament, investigation, crime, theft, abuse.

УДК 343.14

ББК 67.410 .204

ОТДЕЛЬНЫЕ АСПЕКТЫ КРИМИНАЛИСТИЧЕСКОЙ ХАРАКТЕРИСТИКИ ПРЕСТУПЛЕНИЙ, СОВЕРШ АЕМЫХ В СФЕРЕ

ОБОРОННО-ПРОМЫШЛЕННОГО КОМПЛЕКСА РОССИИ, В КОНТЕКСТЕ ПРОБЛЕМЫ ОБЕСПЕЧЕНИЯ НАЦИОНАЛЬНОЙ БЕЗОПАСНОСТИ

\author{
Святослав Юрьевич Бирюков
}

Волгоградская академия МВД России, г. Волгоград, Российская Федерация 


\title{
Надежда Тельмановна Тришина
}

\author{
Волгоградский государственный университет, г. Волгоград, Российская Федерация
}

Введение: нет сомнений, что наличие у государства мощной боеспособной армии в дополнение к развитой и стабильной экономике в условиях современного мира является одной из самых надежных гарантий устойчивого международного положения страны, уважительного и адекватного отношения к ней со стороны других государств, и в конечном счете обеспечения ее национальной безопасности.

Укрепление боеспособности российской армии является в последние годы одним из важнейших национальных проектов. В свою очередь одним из важнейших направлений деятельности в указанной сфере является перевооружение армии, оснащение ее новой военной техникой и современным вооружением.

Безусловную актуальность такой работы подтвердила недавняя операция российских Вооруженных сил в Сирийской Арабской Республике, где были продемонстрированы многократно возросшие возможности современной военной техники - продукта ОПК России. Однако не секрет, что указанные «вливания» денежных средств служат и предпосылкой для их хищений, что, по нашему мнению, является опасным дестабилизирующим фактором, крайне негативно воздействующим на состояние национальной безопасности нашей страны, о чем свидетельствуют доклады Генерального прокурора России Ю.Я. Чайки [8].

Анализ следственной и судебной практики свидетельствует о не всегда удовлетворительном качестве расследования преступлений, совершаемых в сфере ОПК. Качество же это находится в прямой зависимости от уровня криминалистического обеспечения самого процесса расследования, в том числе и от наличия научно обоснованных рекомендаций об организационных основах их раскрытия и расследования.

В связи с этим авторами поставлена цель раскрыть отдельные, наиболее значимые элементы криминалистической характеристики данного вида преступлений. Методы: методологическую основу данного исследования составляет совокупность методов научного познания, среди которых основное место занимают методы обработки информации и логического анализа, синтеза, индукции, дедукции и обобщения. Результаты: представленное в работе авторское наполнение отдельных элементов криминалистической характеристики преступлений, совершаемых в сфере оборонно-промышленного комплекса России, опирающееся на судебно-следственную практику, дает возможность использовать их в практической деятельности уполномоченных должностных лиц правоохранительных органов в ходе выявления и при расследовании вышеназванных преступлений. Выводы: в результате исследования раскрыты отдельные элементы криминалистической характеристики преступлений указанного вида для обучающихся по направлению подготовки «Юриспруденция», педагогических работников юридических вузов, а также практических работников в целях более полного понимания особенностей расследования преступлений в сфере оборонно-промышленного комплекса.

Ключевые слова: национальная безопасность, перевооружение, расследование, преступление, хищение, злоупотребление.

\section{Введение}

Наличие у государства мощной боеспособной армии в условиях современного мира является одной из гарантий устойчивого международного положения такой страны, уважительного и адекватного отношения к ней со стороны других государств.

Президентом и Правительством Российской Федерации принимаются меры по укреплению Вооруженных сил России, их оснащению новой военной техникой и современным вооружением. На указанные цели государством до 2020 г. выделено 20 трлн рублей. Для переоснащения предприятий оборонно-промышленного комплекса страны (далее - ОПК) предусмот- рено выделение 3 трлн руб., а расходы на государственный оборонный заказ (далее - ГОЗ) в 2017 г. составили более 3 трлн руб. [12].

Когда понятие «национальная безопасность» вошло в политический лексикон на Западе, оно использовалось в качестве синонима обороноспособности государства, и фактически к середине 80-х гг. ХХ в. под этим понятием главным образом понимали военную и политическую безопасность. С начала 90-х гг. прошлого столетия в теоретических исследованиях, в философско-социологической и политической литературе понятие «национальная безопасность» и проблему ее обеспечения рассматривают с учетом экономических, социокультурных и других факторов [7]. 
Обороноспособность государства как фактор национальной безопасности

Сегодня в известной мере сформировалось общее понимание базисных категорий, которые используются при решении проблемы национальной безопасности, что способствует разработке достаточно структурированных, снабженных относительно четким понятийным аппаратом руководящих документов по вопросам ее обеспечения. Есть понимание, что национальная безопасность - достаточно сложное социально-политическое явление, которое отображает последствия многогранной жизнедеятельности, накопленный исторический опыт, предпочтения и культуру каждого человека (индивида), общества, государства, в целом земной цивилизации, что оно имеет множество оттенков, закрепленных правом как совокупное состояние, которое аккумулирует бесконечное число видов убытков (потерь), а также возможных представлений об угрозах и их последствиях для интересов национальных [11].

По определению российского политолога Н.А. Косолапова, национальная безопасность это стабильность, которая может поддерживаться на протяжении длительного времени, состояние достаточно разумной динамической защищенности от наиболее существенных из реально существующих угроз и опасностей, а также способность распознавать такие вызовы и своевременно принимать необходимые меры для их нейтрализации [9].

Очевидно, что обороноспособность государства является одним из факторов, обеспечивающих национальную безопасность любого государства, поэтому естественно, что выявление и пресечение фактов хищения и нецелевого расходования бюджетных денежных средств, которые становятся предметом преступного посягательства, эффективное расследование имущественных и должностных преступлений в оборонно-промышленной сфере являются приоритетными направлениями деятельности Министерства внутренних дел Российской Федерации.

В 2017 г. в производстве следователей органов предварительного следствия находи- лось 298 уголовных дел указанной категории (в 2016 г. - 194, в 2015 г. - 106), из которых направлено в суд с обвинительным заключением - 61 уголовное дело (в 2016 г. - 35, в 2015 г. - 15), причем $49 \%$ от числа находившихся в производстве уголовных дел находится в стадии расследования [10].

Размер причиненного ущерба по оконченным уголовным делам составил 3,2 млрд руб., из которых возмещено 1,015 млрд руб. или 31,7 \% (в 2016 г. - 1,1 млрд руб. и 405,6 млн руб. или $37,3 \%$ соответственно) [10].

Размер ущерба от хищений бюджетных денежных средств, выделенных на реализацию ГОЗ, составил 2,2 млрд руб., из которых возмещено около 400 млн руб. [10].

Мониторинг правоприменительной практики показал, что подавляющее большинство преступлений, расследующихся следователями МВД России, квалифицируется по ст. 159, 160 и 201 УК РФ.

Например:

- по ст. 159 ч. 4 УК РФ квалифицированы действия генерального директора ОАО «Дальневосточный завод “Звезда”» А., ряда других руководителей завода и коммерческих организаций-контрагентов, которые в 20092010 гг. похитили 719 млн руб., выделенные для ремонта подводных лодок и надводных кораблей Тихоокеанского флота, путем заключения фиктивных договоров [1];

- по ч. 4 ст. 160 УК РФ квалифицированы действия генерального директора ОАО «АСЗ» Б. и других лиц, совершивших присвоение и растрату выделенных предприятию более 5 млн руб. бюджетных денежных средств. Общий ущерб $\mathrm{OAO}$ «АCЗ» и $\mathrm{AO}$ «ОСК» от действий Б., которому инкриминированы также преступления, предусмотренные по ч. 4 ст. 159 УК РФ и ч. 1, 2 ст. 201 УК РФ, составил 179 млн руб. [6];

- обвинение по ч. 1 ст. 201 УК РФ предъявлено генеральному директору ОАО «Авиаагрегат» В., причинившему указанной организации ущерб на сумму свыше 44 млн руб. при продажепринадлежащих ей помещений и их последующей аренде. По делу установлено, что купившее помещения юридическое лицо зарегистрировано на близкого родственника В., расчетным счетом которого посредством системы «Банкклиент» также управлял В. [5]. 


\section{Наиболее типичные способы совершения преступлений в сфере экономической безопасности и обороноспособности государства}

Таким образом, в основной массе данные преступления с уголовно-правовой точки зрения можно разделить на две категории:

1) хищения (ст. 158, 159, 160 УК РФ);

2) злоупотребление полномочиями (ст. 201 УК РФ).

Изучение следственной и судебной практики позволило выявить наиболее типичные способы совершения преступлений в рассматриваемой сфере.

1. Хищение денежных средств государственного оборонного заказа путем перевода на счета фиктивных юридических лиц либо по фиктивным контрактам.

При совершении преступления указанным способом обвиняемые, обладающие административно-распорядительными полномочиями в органах управления заказчика, заключают договоры с контрагентами, руководителями которых являются их доверенные лица.

Последние, как правило, через структуры, специализирующиеся на регистрации юридических лиц, заранее приобретают фирмы«однодневки» (зарегистрированные на граждан, не имеющих цели предпринимательской деятельности), и, получив денежные средства, переводят их на счета этих организаций, после чего эти денежные средства обналичиваются различными способами. Имеют место факты перечисления денежных средств структурам, осуществляющим их обналичивание на «профессиональной» основе.

Не менее распространенным способом распоряжения похищенными денежными средствами является погашение ранее полученных кредитов или исполнение ранее возникших обязательств, например, по выполнению работ на других строительных объектах или поставке продукции другим контрагентам. Данные обязательства в подавляющем большинстве случаев возникают вследствие предыдущих хищений денежных средств. Имеют место факты систематического погашения ранее возникших обязательств из авансовых средств, получаемых на новых объектах («перекредитование»).
После этого подрядчик (субподрядчик) либо фальсифицирует документы о выполнении работ, либо уклоняется от их выполнения, то есть неисполнение обязательств является не способом хищения, а общественно опасным последствием.

Имеют место факты сговора заказчика и подрядчика (субподрядчика), когда подписываются документы о выполнении работ в полном объеме заключенных договоров при очевидном их невыполнении.

Например, путем невыполнения в полном объеме работ по государственным контрактам с ФГКУ «Пограничное управление ФСБ России по Мурманской области», Министерством обороны РФ, и договору с ОАО «ЦС “Звездочка”», входящим в состав предприятий ОАО «ОСК», на сервисное обслуживание и ремонт кораблей Северного флота России генеральный директор $\mathrm{OOO}$ «XXX» Г. совершил хищение бюджетных денежных средств в размере 32,2 млн руб., перечислив их на расчетные счета организаций, аффилированных лицам из числа руководства ООО «ХХХ» [2].

2. Преступления в сфере корпоративного управления, направленные на вывод активов стратегических предприятий (предприятий ОПК) с последующим переводом их в номинальное владение подконтрольных обвиняемым юридических лиц, в том числе зарегистрированных в офшорных юрисдикциях.

Особенностью преступлений данного вида является то, что непосредственно перед переходом права на имущество создаются фиктивные основания для этого перехода, придающие действиям правомерный вид и исключающие (или существенно затрудняющие) возврат имущества в судебном порядке.

Используются мнимые (фиктивные) сделки следующего вида:

- для создания фиктивной задолженности - безвозмездная выдача векселя подконтрольному юридическому лицу или заключение безденежного договора займа, в результате чего при наступлении срока, установленного векселем или договором, векселедержатель или кредитор приобретает право требования, что позволяет на якобы законных основаниях передать ему похищаемое имущество;

- для регистрации права на имущество без заключения сделок купли-продажи и пос- 
ледующей оплаты - внесение похищаемого имущества в виде взноса в уставной капитал вновь создаваемого юридического лица, в результате чего право собственности переходит к нему и дает право дальнейшего распоряжения этим имуществом;

- для регистрации права на имущество с заключением договоров купли-продажи, но без фактической оплаты - использование при совершении сделки в качестве средства платежа векселей фиктивного юридического лица, с отдаленным во времени сроком погашения, простая отсрочка платежа либо создание ее видимости фиктивными банковскими проводками.

В целях достижения невозможности возврата потерпевшим похищенного у него имущества сделки совершаются неоднократно, до получения новым собственником статуса «добросовестного приобретателя», у которого имущество может быть истребовано в судебном порядке только в том случае, если будет доказано, что он знал о его преступном происхождении.

Для затруднения судебного обжалования в ряде случаев юридические лица, совершившие сделки, ликвидируются путем банкротства или слияния с другими юридическими лицами. В этом случае потерпевшему необходимо дополнительно признать в судебном порядке незаконность ликвидации или слияния.

Наиболее сложным для возврата имущества потерпевшему является переход права собственности к иностранному юридическому лицу, зарегистрированному в государстве с упрощенной системой налогообложения и учреждения юридических лиц, которое обеспечивает максимальную анонимность сведений об участниках (учредителях), бенефициapax, имуществе, счетах и совершаемых сделках (офшоры).

Как правило, в таких юрисдикциях законодательно закреплена необходимость указания в учредительных документах компании сведений о бенефициаре (лице, которое приобретает выгоду от деятельности компании, не являясь формальным учредителем). Таким лицом может быть российский гражданин, в интересах которого совершается вывод активов, и который является организатором совершения преступления.
Например, с использованием векселей «Classide Holdings Limited» была создана система фиктивных долговых обязательств при хищении активов ОАО «Росшельф». Под видом их погашения обвиняемые организовали заключение ряда взаимосвязанных сделок по передаче $100 \%$ доли в уставном капитале ООО «ЦМТ Шельф», в собственности которого находились полные пакеты акций ОАО СКБ «Каспий», ПАО ЦКБ «Коралл» и ОАО КБ «Вымпел». Результатом стал безвозмездный переход корпоративного контроля над указанными конструкторскими бюро к офшорной компании «CNRG Investment Limited», бенефициаром которой является обвиняемый Е. [3].

В результате анализа практики расследования преступлений в сфере ОПК и при исполнении ГОЗ определен примерный состав преступной группы:

1. Должностное лицо органа государственной власти (государственного предприятия), обладающее исполнительно-распорядительными полномочиями при решении вопроса о заключении государственного контракта (гособоронзаказа) или при распоряжении имуществом.

2. Руководитель коммерческой организации, выполняющей роль генерального подрядчика, первого контрагента при приобретении имущества, получении денежных средств. Он имеет высокую степень доверия должностного лица органа государственной власти (государственного предприятия), может состоять с ним в родственной связи, иметь длительные дружеские связи (например, одноклассник), общее прежнее место службы или работы. Как правило, такое предприятие ведет определенную финансово-хозяйственную деятельность и не может быть однозначно отнесено к разряду фиктивных юридических лиц (фирм-«однодневок»).

3. Номинальный директор фиктивного юридического лица, если он возглавляет два и более фиктивных юридических лица, то активно участвует в их деятельности, переговорах, заключении договоров, состоит в штате организации, возглавляемой руководителем коммерческой организации (первого контрагента) особенно на должностях, предполагающих определенную степень доверия (личный 
водитель, секретарь и т. д.), и имеет таким образом возможность оценить и осознать характер преступной деятельности, и в этой связи привлекается к уголовной ответственности в составе группы.

Так, ООО «Инвестиции, возрождение, развитие» являлось одним из «подставных» юридических лиц, через которое имущество ЗАО «Волгоградский металлургический завод “Красный Октябрь”» переводилось в собственность офшорной компании «Red October». Однако генеральный директор ООО И. участвовал в переговорах, контролировал исполнение сделки, а также состоял в советах директоров других компаний, также участвовавших в криминальных схемах вывода имущества. В этой связи он привлечен в качестве обвиняемого.

4. Лица из числа персонала юридических и финансовых служб. Такие лица непосредственно занимаются составлением документов и в ряде случаев в силу своего образования и опыта работы могут быть авторами и разработчиками криминальных схем с последующим их контролем и «авторским сопровождением». В компетенцию данных лиц часто входит подбор номинальных руководителей фирм-«однодневок», организация схем обналичивания денежных средств или связь со структурами, профессионально занимающимися регистрацией юридических лиц или обналичиванием. Могут располагать детальными сведениями о совершении преступления, которые в силу объективных причин неизвестны должностным лицам органа государственной власти (государственного предприятия) и руководителям коммерческой организации (первого контрагента).

Например, К. - доверенное лицо бенефициарного владельца ОАО «Росшельф» Л. - был разработчиком «вексельной» схемы создания системы фиктивных долговых обязательств, позволившей преступной группе осуществить вывод активов ОАО «Росшельф» в офшорную компанию «CNRG Investment Limited» [4].

5. Представители структур, профессионально занимающихся регистрацией юридических лиц или обналичиванием. «Специалисты» данного профиля могут иметься в распоряжении вышеперечисленных организаторов преступления. Если же эти структуры ве- дут самостоятельную профессиональную деятельность, возможно наличие «заказов» от других преступных групп.

При организации хищения денежных средств ОАО «Климовский специализированный патронный завод» («КСПЗ») на сумму 250 млн руб. первый заместитель генерального директора ОАО «КСПЗ» М. дал поручение ранее знакомому Н. приобрести готовые пакеты документов фиктивных юридических лиц, на счета которых потом перечислялись денежные средства по фиктивным договорам, и которыми в дальнейшем Н. управлял по системе дистанционного банковского обслуживания [12].

\section{Выводы}

Оборона государства - это система политических, экономических, социальных и правовых мер по подготовке к вооруженной защите и, собственно, вооруженная защита Российской Федерации, целостности и неприкосновенности ее территории. Анализ материалов уголовных дел позволил выявить наиболее часто встречаемые категории уголовных дел в сфере экономической безопасности и обороноспособности государства, типичные способы совершения преступлений, а также определить примерный состав преступной группы.

\section{СПИСОК ЛИТЕРАТУРЫ}

1. Архив Дальневосточного краевого суда.

2. Архив Мурманского областного суда.

3. Архив Подольского городского суда Московской области.

4. Архив Пресненского районного суда г. Москвы.

5. Архив Самарского областного суда.

6. Архив Хабаровского краевого суда.

7. Борщевский, Г. А. Роль государства в формировании преемственного исторического сознания в контексте проблемы обеспечения национальной безопасности России / Г. А. Борщевский // Информационный гуманитарный портал «Знание. Понимание. Умение». - 2012. - № 1. - Электрон. текстовые дан. - Режим доступа: http:/www.zpujournal.ru/e-zpu/2012/1/Borshchevskiy_ContinualHistorical-Consciousness/ (дата обращения: 12.04.2018). - Загл. с экрана. 
8. Доклад Ю.Я. Чайки на расширенном заседании коллегии Генеральной прокуратуры Российской Федерации // Сайт Генеральной прокуратуры Российской Федерации. - Электрон. текстовые дан. Режим доступа: https://genproc.gov.ru/special/smi/ appearences/13702 (дата обращения: 12.04.2018). Загл. с экрана.

9. Национальная безопасность : учебник / под ред. Н. Д. Эриашвили, О. А. Мироновой, Е. Н. Хазова. - М. : Юнити-Дана, 2017. - 287 с.

10. Официальный сайт Министерства внутренних дел Российской Федерации. - Электрон. текстовые дан. - Режим доступа: https://мвд.рф (дата обращения: 14.04.2018). - Загл. с экрана.

11. Указ Президента РФ «О Стратегии национальной безопасности Российской Федерации» от 31 дек. 2015 г. № 683. - Доступ из справ.-правовой системы «КонсультантПлюс».

12. Юферев, С. Итоги 2017 года для российского оборонно-промышленного комплекса // Военное обозрение. - Электрон. текстовые дан. - Режим доступа: https://topwar.ru/132942-itogi-2017-goda-dlyarossiyskogo-oboronno-promyshlennogo-kompleksa. html (дата обращения: 12.04.2018). - Загл. с экрана.

\section{REFERENCES}

1. Arkhiv Dalnevostochnogo kraevogo suda [Archive of the Far Eastern Regional Court].

2. Arkhiv Murmanskogo oblastnogo suda [Archive of the Murmansk Regional Court].

3. Arkhiv Podolskogo gorodskogo suda Moskovskoy oblasti [Archive of the Podolsk City Court of the Moscow Region].

4. Arkhiv Presnenskogo rayonnogo suda g. Moskvy [Archive of the Presnensky District Court of Moscow].

5. Arkhiv Samarskogo oblastnogo suda [Archive of the Samara Regional Court].

6. Arkhiv Khabarovskogo kraevogo suda [Archive of the Khabarovsk Regional Court].
7. Borshchevskiy G.A. Rol gosudarstva v formirovanii preemstvennogo istoricheskogo soznaniya $\mathrm{v}$ kontekste problemy obespecheniya natsionalnoy bezopasnosti Rossii [The Role of the State in the Formation of a Continuum of Historical Consciousness in the Context of Ensuring National Security of Russia]. Informatsionnyy gumanitarnyy portal «Znanie. Ponimanie. Umenie», 2012, no. 1. URL: http://www.zpu- journal.ru/e-zpu/2012/1/ Borshchevskiy_Continual-Historical-Consciousness. (accessed 12 April 2018).

8. Doklad Yu. Ya. Chayki na rasshirennom zasedanii kollegii Generalnoy prokuratury Rossiyskoy Federatsii [Yu.Ya. Chayka's Report at the Extended Meeting of the Collegium of the General Prosecutor's Office of the Russian Federation]. Sayt Generalnoy prokuratury Rossiyskoy Federatsii [Website of the General Prosecutor's Office of the Russian Federation]. URL: https:/genproc.gov.ru/special/smi/appearences/ 13702 (accessed 12 April 2018).

9. Eriashvili N.D., Mironova O.A., Khazov E.N., eds. Natsionalnaya bezopasnost: uchebnik [National Security: Textbook]. Moscow, Yuniti-Dana Publ., 2017. $287 \mathrm{p}$.

10. Ofitsialnyy sayt Ministerstva vnutrennikh del Rossiyskoy Federatsii [The Official Website of the Ministry of Interior of the Russian Federation]. URL: https://mvd.rf. (accessed 14 April 2018).

11. Ukaz Prezidenta $R F \ll O$ Strategii natsionalnoy bezopasnosti Rossiyskoy Federatsii» ot 31 dek. 2015 g. № 683 [Decree of the President of the Russian Federation 'On the Strategy of National Security of the Russian Federation' of December 31, 2015 No. 683]. Access from Reference Legal System KonsultantPlyus.

12. Yuferev S. Itogi 2017 goda dlya rossiyskogo oboronno-promyshlennogo kompleksa [Results of 2017 for the Russian Defense Industry Complex]. Voennoe obozrenie [Military Review]. URL: https:// topwar.ru/132942-itogi-2017-goda-dlya-rossiyskogooboronno-promyshlennogo-kompleksa.html. (accessed 12 April 2018).

\section{Information about the Authors}

Svyatoslav Yu. Biryukov, Candidate of Sciences (Jurisprudence), Associate Professor, Head of Department of Preliminary Investigation, Educational and Scientific Complex on Preliminary Investigation in the Internal Affairs Bodies, Volgograd Academy of the Ministry of Interior of Russia, Istoricheskaya St., 130, 400131 Volgograd, Russian Federation, Bir.slav@yandex.ru.

Nadezhda T. Trishina, Candidate of Sciences (Jurisprudence), Senior Lecturer, Department of Criminal Procedure and Criminalistics, Volgograd State University, Prosp. Universitetsky, 100, 400062 Volgograd, Russian Federation, abrekova@mail.ru. 


\section{Информация об авторах}

Святослав Юрьевич Бирюков, кандидат юридических наук, доцент, начальник кафедры предварительного расследования учебно-научного комплекса по предварительному следствию в органах внутренних дел, Волгоградская академия МВД России, ул. Историческая, 130, 400131 г. Волгоград, Российская Федерация, Bir.slav@yandex.ru.

Надежда Тельмановна Тришина, кандидат юридических наук, старший преподаватель кафедры уголовного процесса и криминалистики, Волгоградский государственный университет, просп. Университетский, 100, 400062 г. Волгоград, Российская Федерация, abrekova@mail.ru. 